\title{
Hypothermia in a surgical intensive care unit
} Fernando J Abelha*1, Maria A Castro ${ }^{1}$, Aida M Neves ${ }^{1}$, Nuno M Landeiro ${ }^{1}$ and Cristina C Santos ${ }^{2}$

\author{
Address: ${ }^{1}$ Department of Anesthesia and Intensive Care, Hospital de São João, Porto, Portugal and ${ }^{2}$ Biostatistics and Medical Informatics \\ Department, Faculty of Medicine at the University of Porto, Portugal \\ Email: Fernando J Abelha* - abelha@mail.telepac.pt; Maria A Castro - fbee@netcabo.pt; Aida M Neves - aneves@hsjoao.min-saude.pt; \\ Nuno M Landeiro - nunolandeiro@mail.telepac.pt; Cristina C Santos - csantos@med.up.pt \\ * Corresponding author
}

Published: 06 June 2005

BMC Anesthesiology 2005, 5:7 doi:10.1 I86/147|-2253-5-7
Received: 15 January 2005

Accepted: 06 June 2005

This article is available from: http://www.biomedcentral.com/I47/-2253/5/7

(C) 2005 Abelha et al; licensee BioMed Central Ltd.

This is an Open Access article distributed under the terms of the Creative Commons Attribution License (http://creativecommons.org/licenses/by/2.0), which permits unrestricted use, distribution, and reproduction in any medium, provided the original work is properly cited.

\begin{abstract}
Background: Inadvertent hypothermia is not uncommon in the immediate postoperative period and it is associated with impairment and abnormalities in various organs and systems that can lead to adverse outcomes. The aim of this study was to estimate the prevalence, the predictive factors and outcome of core hypothermia on admission to a surgical ICU.

Methods: All consecutive 185 adult patients who underwent scheduled or emergency noncardiac surgery admitted to a surgical ICU between April and July 2004 were admitted to the study. Tympanic membrane core temperature (Tc) was measured before surgery, on arrival at ICU and every two hours until 6 hours after admission. The following variables were also recorded: age, sex, body weight and height, ASA physical status, type of surgery, magnitude of surgical procedure, anesthesia technique, amount of intravenous fluids administered during anesthesia, use of temperature monitoring and warming techniques, duration of the anesthesia, ICU length of stay, hospital length of stay and SAPS II score. Patients were classified as either hypothermic $\left(\mathrm{Tc} \leq 35^{\circ} \mathrm{C}\right)$ or normothermic $\left(T c>35^{\circ} \mathrm{C}\right)$. Univariate analysis and multiple regression binary logistic with an odds ratio $(\mathrm{OR})$ and its $95 \%$ Confidence Interval $(95 \% \mathrm{Cl})$ were used to compare the two groups of patients and assess the relationship between each clinical predictor and hypothermia. Outcome measured as ICU length of stay and mortality was also assessed.
\end{abstract}

Results: Prevalence of hypothermia on ICU admission was $57.8 \%$. In univariate analysis temperature monitoring, use of warming techniques and higher previous body temperature were significant protective factors against core hypothermia. In this analysis independent predictors of hypothermia on admission to ICU were: magnitude of surgery, use of general anesthesia or combined epidural and general anesthesia, total intravenous crystalloids administrated and total packed erythrocytes administrated, anesthesia longer than 3 hours and SAPS II scores. In multiple logistic regression analysis significant predictors of hypothermia on admission to the ICU were magnitude of surgery (OR 3.9, 95\% Cl, I.4-10.6, $p=0.008$ for major surgery; OR 3.6, 95\% Cl, I.5-9.0, $p=0.005$ for medium surgery), intravenous administration of crystalloids (in litres) (OR I.4, $95 \% \mathrm{Cl}, \mathrm{I} . \mathrm{I}-\mathrm{I.7}, \mathrm{p}=0.0 \mathrm{I}$ ) and SAPS score (OR I.0, 95\% Cl I.0-I.7, $\mathrm{p}=0.0 \mathrm{I}$ ); higher previous temperature in ward was a significant protective factor (OR $0.3,95 \% \mathrm{Cl} 0.1-0.7, \mathrm{p}=0.003)$. Hypothermia was neither a risk factor for hospital mortality nor a predictive factor for staying longer in ICU.

Conclusion: The prevalence of patient hypothermia on ICU arrival was high. Hypothermia at time of admission to the ICU was not an independent factor for mortality or for staying longer in ICU. 


\section{Background}

Hypothermia is defined as a core body temperature of less than $35^{\circ} \mathrm{C}$ and may be classified as mild $\left(32^{\circ} \mathrm{C}-35^{\circ} \mathrm{C}\right)$, moderate $\left(28^{\circ} \mathrm{C}-32^{\circ} \mathrm{C}\right)$ and severe $\left(<28^{\circ} \mathrm{C}\right)[1-4]$.

Hypothermia promotes impairment and abnormalities in various organs and systems that can lead to a decrease in oxygen release into the tissues [5] and include depression in myocardial contractility, peripheral vasoconstriction $[6,7]$ ventilation-perfusion mismatch, increased blood viscosity and shifts to the left in the oxyhemoglobin-dissociation curve $[8,9]$. Hypothermia also reduces platelet function [10-12] and decreases the activation of the coagulation cascade [13] and may result in coagulopathy $[14,15]$.

Inadvertent core hypothermia is often found in the immediate postoperative period especially in high risk surgical patients $[9,16]$. Anesthesia impairs central thermoregulation, allowing re-distribution of body heat $[17,18]$. Cool ambient temperatures and high volume fluid administration accelerate loss of heat to the environment. The initial response to cold stress is to generate and conserve temperature via the activation of the sympathetic nervous system. In the postoperative period, hypothermia is often complicated by shivering and peripheral vasoconstriction. The consequences of shivering include an increase in cardiac and systemic energy demand, raising oxygen consumption and carbon dioxide production and an increase in cardiac work $[19,20]$. Randomized control trials have proven that mild hypothermia can lead to an increased incidence of surgical wound infection [21], myocardial ischemia and cardiac arrhythmias [22], impaired coagulation and immune response $[11,23]$; other complications include enhanced anesthesia drug effects [24,25], shivering $[20,26]$, prolonged recovery room stays and delayed discharge from the post anesthesia care and from hospital [27].

On the basis of review of the literature, the most important risk factors for the development of hypothermia in the perioperative period include age $[28,29]$, sex $[9,30,31]$, body weight and body surface area [16,32], preoperative body temperature [16,33] history of diabetic neuropathy [34], emergency surgery [30], ASA physical status [16], surgical procedure in which major body cavities or major vessels are exposed $[9,16]$, anesthetic technique [31] warming method [35], amount of intravenous replacement [30], duration of anesthesia or surgery $[9,16,30,31]$ and ambient operating room temperature $[16,28]$.

With the progress in surgery and anesthesia more advanced technology was introduced, procedures are using more complex techniques, lasting longer and some- times are made with larger incisions. These procedures are done in older and severely ill patients who present significant underlying medical problems and have sometimes undergone previous extensive surgery. The choice of anesthesia technique is also changing and combined epidural and general anesthesia are being used more often. These are reasons that may increase risk of intraoperative and immediate postoperative hypothermia. Whereas effective warming measures are available [35] and more information about the adverse effects of hypothermia has been reported, the incidence of hypothermia at the time of admission to the surgical ICU is still frequent $[22,29,30]$. Re-identifying significant predictive factors would help in decreasing this incidence. Such information could be helpful to prevent unnecessary risks and adverse outcomes and could decrease the current frequent incidence of hypothermia.

The purpose of this study was to estimate the prevalence of hypothermia on admission to a surgical ICU and retrospectively identify their clinical predictors. A second objective was to prospectively evaluate the outcome measured in terms of ICU length of stay (LOS) and hospital mortality.

\section{Methods}

The protocol was approved by our institutional review board, and written consent was obtained from the patients. All consecutive postoperative patients, aged 18 years or older, who underwent scheduled or emergency noncardiac surgery, admitted to a nine bed surgical ICU of a tertiary care hospital during a three month period between April and July 2004, were eligible for the study. Temperature of the operating room was not controlled for every patient because the air conditioning system is automatically settled to a temperature room from $20^{\circ} \mathrm{C}$ to $22^{\circ} \mathrm{C}$. This fact was confirmed by a pilot study in which operating room temperature was measured using thermocouples placed near patients but away from any heat-generating equipment.

Core temperature (Tc) was measured by an infrared tympanic membrane thermometer (ThermosScan ${ }^{\circledR}$ Type 6014 Pro 3000 , WelchAllyn, with an accuracy of $\pm 0.03^{\circ} \mathrm{C}$ in the range of $20^{\circ} \mathrm{C}-42.2^{\circ} \mathrm{C}$ - Welch Allyn Medical Products, NY, USA) [36,37]. This instrument was maintained and calibrated in accordance with the manufacturer's guidelines. These tympanic membrane temperatures were obtained before surgery in the ward, on arrival at ICU and every two hours until 6 hours after admission by experienced nurses trained to measure tympanic membrane temperatures.

The following clinical variables were recorded on admission to the ICU: age, sex, body weight and height, 
Table I: Patient baseline characteristics $(n=185)$

\begin{tabular}{|c|c|}
\hline Variable & mean \pm SD or median and range or number $(\%)$ \\
\hline Age & Median 67, mean $66.0 \pm 12.6($ range, $25-94)$ \\
\hline$<65 / \geq 65$ & $79 / 106$ \\
\hline Male / Female & $112(60.5) / 73(39.5)$ \\
\hline Body mass index $(\mathrm{Kg} / \mathrm{m} 2)$ & $25.4 \pm 5.9($ range, $15.6-57.6)$ \\
\hline Previous temperature in the ward $\left({ }^{\circ} \mathrm{C}\right)$ & $36.37 \pm 0.49($ range, $35.00-38.60)$ \\
\hline \multicolumn{2}{|l|}{ ASA Physical status } \\
\hline I & $5(2.7)$ \\
\hline II & $72(38.9)$ \\
\hline III & $90(48.6)$ \\
\hline IV & $18(9.7)$ \\
\hline Emergency surgery & $29(15.7)$ \\
\hline \multicolumn{2}{|l|}{ Magnitude of surgery } \\
\hline Minor & $36(19.5)$ \\
\hline Medium & $45(24.3)$ \\
\hline Major & $104(56.2)$ \\
\hline General anesthesia & $158(85.4)$ \\
\hline Regional anesthesia & $19(10.3)$ \\
\hline Combined anesthesia & $7(3.8)$ \\
\hline Temperature monitoring & $22(11.9)$ \\
\hline Warming technique & $81(43.8)$ \\
\hline Intravenous crystalloids (L.) & $2.85 \pm 1.65($ range $0.20-10.50)$ \\
\hline Intravenous colloids (L.) & $0.09 \pm 0.26($ range $0-1.500)$ \\
\hline Packed erythrocytes (Units) & $0.7 \pm 1.3($ range, $0-7)$ \\
\hline Fresh frozen plasma (Units) & $0.2 \pm 0.9($ range, $0-9)$ \\
\hline Duration of anesthesia (min.) & $218 \pm 108($ range, $44-660)$ \\
\hline$>180 \mathrm{~min}$. & $94(50.8)$ \\
\hline Temperature on admission & $34.69 \pm 1.02(32.1-38.2)$ \\
\hline$\leq 35$ & $107(57.8)$ \\
\hline Temperature 2 hours after admission & $35.34 \pm 0.85(32.4-38.3)$ \\
\hline$\leq 35$ & $48(25.9)$ \\
\hline Temperature 4 hours after admission & $35.90 \pm 0.80(32.5-38.4)$ \\
\hline$\leq 35$ & $16(8.8)$ \\
\hline Temperature 6 hours after admission & $36.12 \pm 0.73(33.4-38.5)$ \\
\hline$\leq 35$ & $9(5)$ \\
\hline Score of Acute Physiologic system (SAPS II) & $24.4 \pm 14.0$ (range $3-74)$ \\
\hline Length of ICU stay (days) & median 0.92 ; percentile $25,0.79$; percentile $75,2.1$ I range $(0.08-82)$ \\
\hline$>2$ days & $47(25.4)$ \\
\hline Length of hospital stay (days) & median 15; percentile 25,10 ; percentile $75,29.5$ range $1-170$ \\
\hline Mortality in the ICU & $14(7.60)$ \\
\hline Mortality in the Hospital & $29(15.70)$ \\
\hline
\end{tabular}

preoperative body temperature, ASA physical status, emergency or scheduled surgery, magnitude of surgical procedure as major (surgery in which body cavities or major vessels are exposed to ambient temperature such as major abdominal, thoracic, major vascular, thoracic spine surgery with instrumentation, or hip arthroplasty), medium (surgery in which body cavities are exposed to a lesser degree such as appendectomy), and minor surgery (superficial surgery), anesthesia technique, amount of intravenous crystalloids, colloids, packed erythrocytes and fresh frozen plasma administered during surgery, use of temperature monitoring and warming techniques, and duration of the anesthesia.
The LOS and the mortality in ICU and in hospital were also recorded for all patients, as well as the Simplified Acute Physiology Score II (SAPS II) was calculated [38].

The prevalence of core hypothermia on admission to the ICU and its 95\% Confidence Interval (CI) were calculated by using the cut off point of Tc $35.0^{\circ} \mathrm{C}$. That was used to classify patients as either hypothermic $\left(\mathrm{Tc}<35^{\circ} \mathrm{C}\right.$ on admission to ICU) or normothermic (Tc $\geq 35^{\circ} \mathrm{C}$ on admission to ICU). All hypothermic patients were treated with passive and active external rewarming measures that include synthetic covers and a convective air-warming system using heated air blanket units. The two groups were 
compared to assess the relationship between each clinical predictor and core hypothermia using univariate analysis performed by simple binary logistic regression with an odds ratio (OR) and its 95\% CI and independent sample t test, $\chi^{2}$ test or Fisher's exact test. A multiple regression binary logistic with forward conditional elimination was used to examine covariate effects of each factor on core hypothermia, ICU LOS and hospital mortality and to calculate OR and their 95\% CI. Covariates with a univariate $\mathrm{p}<0.1$ in the respective univariate analysis were entered in these models. In the model for ICU LOS and hospital mortality the categorical variable temperature on admission was also entered. A two-sided significance level of 0.05 was used for all analyses.

Quantitative variables are presented as mean \pm SD. All analyses were performed using SPSS for Windows (version 12.0, Chicago, IL).

\section{Results}

All 185 patients (Table 1 ) were included in the study. The mean $\left( \pm \mathrm{SD}\right.$ ) admission Tc was $34.7^{\circ} \mathrm{C} \pm 1.0^{\circ} \mathrm{C}$ (range, $32.1^{\circ} \mathrm{C}-38.2^{\circ} \mathrm{C}$, first quartile, $34.1^{\circ} \mathrm{C}$, third quartile $35.4^{\circ} \mathrm{C}$ ). Prevalence of core hypothermia on ICU admission was 57.8\% (95\% CI, 54.2\%-61.6\%). Ten patients were admitted with a Tc $<33.0^{\circ} \mathrm{C}$.

The prevalence of hypothermia two hours, four hours and six hours after admission was respectively 26,0\% (95\% CI, $25.6 \%-26.3 \%$ ), $8.8 \%$ (95\% CI, 8.6\%-9.1\%) and 5,0\% (95\% CI, 4.8\%-5,1\%).

According to univariate analysis (Table 2), age, sex, body weight or body mass index, amount of intraoperative colloids and plasma volume, ASA physical status, emergency surgery, surgery longer than 180 minutes were not predictive of core hypothermia at ICU admission.

Table 2: Univariate Analysis of categorical and continuous predictors of core hypothermia

\begin{tabular}{|c|c|c|c|}
\hline Variable & $\begin{array}{c}\text { Hypotermic / non- } \\
\text { hypothermic }\left(n^{\circ} \text { or mean } \pm\right. \\
\text { sd) }\end{array}$ & Odds ratio $(95 \% \mathrm{Cl})$ & p-value \\
\hline \multicolumn{4}{|l|}{ Age (years) } \\
\hline$<65$ & $44 / 35$ & 1 & \\
\hline$\geq 65$ & $63 / 43$ & $0.9(0.5-1.6)$ & 0.611 \\
\hline \multicolumn{4}{|l|}{ Gender } \\
\hline Female & $39 / 34$ & 1 & \\
\hline Male & $68 / 44$ & $0.7(0.4-1.4)$ & 0.327 \\
\hline Body weight $(\mathrm{Kg})$ & $69.19 \pm 16.79 / 68.49 \pm 16.06$ & $1,0(1.0-1.0)$ & 0.771 \\
\hline Body mass index $(\mathrm{Kg} / \mathrm{m} 2)$ & $25.30 \pm 5.77 / 25.58 \pm 6.14$ & $1,0(0.9-1.0)$ & 0.750 \\
\hline Previous temperature in the ward $\left({ }^{\circ} \mathrm{C}\right)$ & $36.28 \pm 0.44 / 36.49 \pm 0.54$ & $0.4(0.2-0.8)$ & 0.007 \\
\hline \multicolumn{4}{|l|}{ ASA Physical status } \\
\hline I & $3 / 2$ & I & \\
\hline II & $43 / 29$ & $1.5(0.2-\mid \mathrm{I} .2)$ & 0.693 \\
\hline III & $52 / 38$ & $1.5(0.5-4.2)$ & 0.457 \\
\hline IV & $9 / 9$ & $1.4(0.5-3.8)$ & 0.544 \\
\hline Emergency surgery & $|8 / 1|$ & $0.8(0.4-1.8)$ & 0.616 \\
\hline \multicolumn{4}{|l|}{ Magnitude of surgery } \\
\hline Minor & $11 / 25$ & I & \\
\hline Medium & $26 / 19$ & $3.1(1.2-7.8)$ & 0.016 \\
\hline Major & $70 / 34$ & $4.7(2.1-10.6)$ & $<0.001$ \\
\hline General anesthesia & $93 / 65$ & $6,0(1.9-18.8)$ & 0.002 \\
\hline Regional anesthesia & $4 / 15$ & 1 & \\
\hline Combined anesthesia & $6 / 1$ & $22.5(2.1-244.8)$ & 0.011 \\
\hline Temperature monitoring & $19 / 3$ & $0.2(0.1-0.7)$ & 0.009 \\
\hline Warming technique & $55 / 26$ & $0.5(0.3-0.9)$ & 0.015 \\
\hline Intravenous crystalloids (L.) & $3.21 \pm 1.75 / 2.37 \pm 1.35$ & $1.4(1.2-1.8)$ & 0.001 \\
\hline Intravenous colloids (L.) & $0.08 \pm 0.26 / 0.10 \pm 0.26$ & $0.7(0.2-2.2)$ & 0.565 \\
\hline Packed erythrocytes (Units) & $0.92 \pm 1.45 / 0.37 \pm 0.81$ & $1.6(1.1-2.2)$ & 0.006 \\
\hline Fresh frozen plasma (Units) & $0.27 \pm 0.81 / 0.19 \pm 1.08$ & $1.1(0.8-1.6)$ & 0.575 \\
\hline \multicolumn{4}{|l|}{ Duration of anesthesia (min.) } \\
\hline$\leq 180 \mathrm{~min}$ & $46 / 45$ & 1 & \\
\hline$>180 \mathrm{~min}$. & $61 / 33$ & $1.8(1.0-3.3)$ & 0.049 \\
\hline Score of Acute Physiologic system (SAPS II) & $26.45 \pm 14.95 / 21.51 \pm 12.14$ & $1.0(1.0-1.1)$ & 0.020 \\
\hline
\end{tabular}


Table 3: Predictors of core hypothermia by multiple logistic regression

\begin{tabular}{lcc}
\hline \multicolumn{1}{c}{ Variable } & Odds ratio $\mathbf{( 9 5 \% ~ C l )}$ & p-value \\
\hline Magnitude of surgery & & 0.005 \\
$\quad$ Medium & $3.6(1.5-9.0)$ & 0.008 \\
$\quad$ Major & $3.9(1.4-10.6)$ & 0.012 \\
Intravenous crystalloids (L) & $1.4(1.1-1.7)$ & 0.003 \\
Previous temperature in the ward & $0.3(0.1-0.7)$ & 0.014 \\
Score of Acute Physiologic system (SAPS II) & $1.0(1.0-1.7)$ & \\
\hline
\end{tabular}

Model adjusted to: previous temperature in the ward, magnitude of surgical procedure, type of anesthesia, use of temperature monitoring, use of warming technique, total intravenous crystalloids, total packed erythrocytes, duration of anesthesia and SAPS II score

Table 4: Predictors of ICU LOS longer than two days by multiple logistic regression

\begin{tabular}{lcc}
\hline \multicolumn{1}{c}{ Variable } & Odds ratio (95\% Cl) & p-value \\
\hline ASA III/IV & $3.4(1.3-9.0)$ & 0.012 \\
SAPS II & $1.1(1.1-1.1)$ & $<0.001$ \\
Intravenous crystalloids (L.) & $1.3(1.0-1.7)$ & 0.023 \\
\hline
\end{tabular}

Model adjusted to: temperature on admission, previous temperature in the ward, magnitude of surgery, type of anesthesia, use of temperature monitoring, use of warming technique, total intravenous crystalloids, total packed erythrocytes, duration of anesthesia, BMI, ASA and SAPS II score.

Temperature monitoring (OR 0.2, 95\% CI 0.1-0.7, $\mathrm{p}=$ 0.009 ), use of warming techniques (OR $0.5,95 \%$ CI $0.3-$ $0.9, \mathrm{p}=0.015)$ and higher previous body temperature (OR 0.4, 95\% CI 0.2-0.8, p = 0.007) were significant protective factors against core hypothermia.

Significant independent predictors of hypothermia on admission were the magnitude of surgery (OR 3.1, 95\% CI $1.2-7.8, \mathrm{p}=0.016$ for medium surgery; OR 4.7, 95\% CI 2.1-10.6, $\mathrm{p}<0.001$ for major surgery), use of general anesthesia or combined epidural and general anesthesia (OR 6.0, 95\% CI, 1.9-18.8, p = 0.002 for general anesthesia; OR 22.5, 95\% CI 2.1-244.8, p = 0.011 for combined epidural and general anesthesia), amount of intravenous crystalloids (OR 1.4, 95\% CI 1.2-1.8, p = 0.001) and number of total units of packed erythrocytes (OR 1.6, $95 \%$ CI $1.1-2.2, \mathrm{p}=0.006)$, anesthesia longer than 3 hours (OR, 1.8; 95\% CI, 1.0-3.3, $\mathrm{p}=0.049)$ and SAPS II scores (OR 1.0, 95\% CI 1.0-1.1, p = 0.020).

Table 3 displays the results of the multiple regression binary logistic analysis. In this model higher preoperative body temperature (OR $0.3,95 \%$ CI $0.1-0.7, \mathrm{p}=0.003$ ) is seen as a significant protective factor against core hypothermia. In this analysis the higher the SAPS II of the patient is, the higher the risk of core hypothermia (OR $1.0,95 \%$ CI $1.0-1.7, \mathrm{p}=0.014)$. The magnitude of surgery (OR 3.9, 95\% CI, 1.4-10.6, p = 0.008 for major surgery; OR 3.6, 95\% CI, 1.5-9.0, $\mathrm{p}=0.005$ for medium surgery) and total intravenous crystalloids (in litres) (OR 1.4, 95\% CI, 1.1-1.7, $\mathrm{p}=0.012$ ) were considerably significant risk factors.

No significant relationship between hypothermia at ICU admission and LOS in hospital or in ICU was to be found.

As can be seen in table 1, ICU LOS varied from 0.1 to 82 days with median of 0,9 days (percentile 25,0.8 days and percentile $75,2.1$ days). The percentage of patients who stayed in ICU longer than 2 days were $25.4 \%(n=47)$.

Multiple regression logistic analysis was used to examine covariate effects of each factor on ICU LOS (table 4). In this analysis the regression model included temperature on admission and all variables that showed statistical significance in the univariate analysis made for predictors of hypothermia and for mortality. This analysis showed that significant risk factors for staying longer in ICU were SAPS II (OR 1.1, 95\% CI 1.1-1.1, p < 0.001), ASA physical status (OR 3.4, 95\% CI 1.3-9.0, $\mathrm{p}=0.012$ for ASA III/IV patients) and amount of intravenous crystalloids administered (OR 1.3, 95\% CI 1.0-1.7, $\mathrm{p}=0.023$ ).

Fourteen (7.6\%) patients died in ICU and 29 (15.7\%) died during their hospitalization.

According to univariate analysis (table 5), age, sex, anesthesia technique, use of a perioperative warming 
Table 5: Univariate Analysis of categorical and continuous predictors of mortality in the hospital

\begin{tabular}{|c|c|c|c|}
\hline Variable & $\begin{array}{c}\text { nonsurvivors / survivors } n^{\circ} \text { or } \\
\text { mean } \pm \text { SD }\end{array}$ & Odds ratio $(95 \% \mathrm{Cl})$ & p-value \\
\hline \multicolumn{4}{|l|}{ Age (years) } \\
\hline$<65$ & $14 / 65$ & 1 & \\
\hline$\geq 65$ & $|5 / 9|$ & $1.3(0.6-2.9)$ & 0.510 \\
\hline \multicolumn{4}{|l|}{ Gender } \\
\hline Male & $19 / 93$ & $0.8(0.3-1.8)$ & 0.551 \\
\hline Female & $10 / 63$ & & \\
\hline Body weight (Kg) & $63.2 \pm 11.8 / 69.8 \pm 16.9$ & $1.0(0.9-1.0)$ & 0.044 \\
\hline Body mass index $(\mathrm{Kg} / \mathrm{m} 2)$ & $23.1 \pm 3.83 / 25.8 \pm 6.1$ & $0.9(0.8-1.0)$ & 0.019 \\
\hline \multicolumn{4}{|l|}{ ASA Physical status } \\
\hline $\mathrm{I} / \mathrm{II}$ & $8 / 69$ & 1 & \\
\hline $\mathrm{III} / \mathrm{IV}$ & $21 / 87$ & $2.1(0.8-5.0)$ & 0.10 \\
\hline Emergency surgery & $13 / 16$ & $7.1(2.9-17.4)$ & $<0.001$ \\
\hline \multicolumn{4}{|l|}{ Magnitude of surgery } \\
\hline Minor & $2 / 34$ & $\mathrm{I}$ & \\
\hline Medium & $11 / 34$ & $3.1(0.7-14.2)$ & 0.146 \\
\hline Major & $16 / 88$ & $5.5(1.1-26.7)$ & 0.034 \\
\hline Temperature monitoring & $5 / 17$ & $1.7(0.6-5.1)$ & 0.337 \\
\hline Warming technique & $|0 / 7|$ & $1.6(0.7-3.6)$ & 0.274 \\
\hline Intravenous crystalloids (L.) & $2.88 \pm 1.59 / 2.85 \pm 1.66$ & $1.0(0.8-1.3)$ & 0.904 \\
\hline Intravenous colloids (L.) & $0.16 \pm 0.33 / 0.08 \pm 0.24$ & $2.4(0.7-8.7)$ & 0.174 \\
\hline Packed erythrocytes (Units) & $0.83 \pm 1.14 / 0.66 \pm 1.27$ & I.I $(0.8-\mathrm{I} .5)$ & 0.508 \\
\hline Fresh frozen plasma (Units) & $0.17 \pm 0.54 / 0.25 \pm 0.99$ & $0.9(0.5-1.5)$ & 0.683 \\
\hline Duration of anesthesia (min.) & $204 \pm 112 / 221 \pm 107$ & & \\
\hline$\leq 180 \mathrm{~min}$ & $16 / 75$ & 1 & \\
\hline$>180 \mathrm{~min}$. & $|3 / 8|$ & $1.3(0.6-3.0)$ & 0.484 \\
\hline \multicolumn{4}{|l|}{ Temperature on admission } \\
\hline$\leq 35$ & $20 / 87$ & 1 & \\
\hline$>35$ & $9 / 69$ & $0.6(0.2-1.3)$ & 0.190 \\
\hline $\begin{array}{l}\text { Score of Acute Physiologic system } \\
\text { (SAPS II) }\end{array}$ & $41.41 \pm 17.86 / 21.20 \pm 10.54$ & $1.1(1.1-1.1)$ & $<0.001$ \\
\hline \multicolumn{4}{|l|}{ Length of ICU stay (days) } \\
\hline$\leq 2$ days & $10 / 128$ & 1 & \\
\hline$>2$ days & $19 / 28$ & $8.7(3.7-20.7)$ & $<0.001$ \\
\hline Length of hospital stay (days) & $45.7 \pm 41.8 / 21.8 \pm 21.9$ & $1.0(1.0-1.0)$ & $<0.001$ \\
\hline
\end{tabular}

technique, temperature monitoring, duration of anesthesia or surgery were not independent risk factors for mortality in the hospital, as temperature was not a risk factor on admission, neither at two, four and six hours after arrival at ICU.

Statistically significant independent risk factors for hospital mortality were low body weight (OR 1.0, 95\% CI 0.9$1.0, \mathrm{p}=0.044$ ) and low body mass index (OR 0.9, 95\% CI $0.8-1.0, \mathrm{p}=0.019$ ), emergency surgery (OR 7.1, 95\% CI 2.9-17.4, $\mathrm{p}<0.001$ ), major surgery (OR 5.5, 95\% CI $1.1-$ 26.7, $\mathrm{p}=0.034$ ), high SAPS II scores (OR 1.1, 95\% CI 1.1$1.1, \mathrm{p}<0.001$ ), longer stay in ICU (OR 8.7, 95\% CI 3.720.7, $\mathrm{p}<0.001$ for ICU LOS longer than 2 days) and in the hospital (OR 1.0, 95\% CI 1.0-1.0, p < 0.001).
The multiple regression logistic analysis (table 6) showed that considerably significant factors predicting death in the hospital were higher SAPS scores (OR 1.1, 95\% CI $1.0-1.1, \mathrm{p}<0.001$ ) and ICU LOS (OR 1.2, 95\% CI 1.1$1.3, \mathrm{p}=0.003)$. This analysis showed that these were the factors that more significantly predicted death in the inhospital setting.

\section{Discussion}

Only noncardiac surgical patients were enrolled in the study. Since none of them underwent a neurosurgical procedure, hypothermia as a therapeutic tool had not been applied.

The prevalence of hypothermia on arrival at ICU was important and proved higher than in other studies 
Table 6: Predictors of mortality by multiple logistic regression

\begin{tabular}{llc}
\hline \multicolumn{1}{c}{ Variable } & Odds ratio $(95 \% \mathrm{CI})$ & p-value \\
\hline SAPS II & $1.1(1.0-1.1)$ & $<0.001$ \\
Length of ICU stay (days) & $1.2(1.1-1.3)$ & 0.003 \\
\hline
\end{tabular}

Model adjusted to: temperature on admission to the ICU, BMI, body weight, magnitude of surgery, type of surgery, SAPS II score, ICU LOS and hospital LOS.

$[6,9,16,29,30]$ although not all of them have chosen the same defining criteria to consider patients hypothermic.

In this study, warmer preoperative body temperature is considered a significant protective factor for hypothermia what was also demonstrated previously [16,33]. This result supports the suggestion that efforts should be done to increase body temperature before surgery. In this context is the idea of increasing operating room temperature to prevent heat loss. Various studies have showed that increasing operating room temperature could prevent core hypothermia $[16,39]$, however, when the operating room is too warm, that is not a comfortable working environment and may even increase the risk of infection $[21,40]$.

Previous studies have shown that older patients [9,30,31] and those with higher ASA physical status [16] had an increased risk for hypothermia. Our study could not confirm these results. We think that may be explained because these patients had more often benefited from any perioperative method of warming and monitoring. In fact, monitoring temperature and the use of techniques to warm patients have demonstrated as protective measures according to our results.

We found that as measured by SAPS II score the more severely ill the patients, the more the probability of arriving hypothermic at ICU.

Although the objective of this study was exploring preadmission clinical factors to hypothermia, we included SAPS in the list of predictive values because this way we could have a measure of severity of illness in the patients admitted to ICU. Measured after admission to ICU, this score reflects not only the pre admission physiologic alterations but also variables like age and co morbidities that were not altered with admission. Only with this premises should the predictive value of SAPS II be evaluated.

Hypothermia is a common occurrence of postoperative period particularly if major body cavities are exposed for long periods of time and other important contributors like the use of intraoperative large amount of intravenous fluids, prolonged operative time and use of general anesthesia or combined anesthesia (general and loco regional anesthesia) are present. In our study, the magnitude of surgery was an independent risk factor for core hypothermia what is in agreement with other studies $[9,16]$ and like other studies $[9,16,30,31]$ that found that duration of anesthesia or surgery are risk factors for hypothermia, we concluded that anesthesia lasting longer than 3 hours was a predictor of core hypothermia with statistical significance. If patients undergoing major procedures with long lasting anesthesia became hypothermic more often, they were probably not warmed actively as we could suspect from the active warming rate and rate of temperature monitoring of this set of patients.

We concluded that the amount of intravenous intraoperative crystalloids was a significant risk factor for developing hypothermia on arrival on ICU and that was already identified in previous studies $[9,30]$. In fact the infusion of crystalloid solutions at room temperature may significantly contribute to intraoperative hypothermia because warming fluids to core temperature requires body heat. Several studies had demonstrated that infusion of warmed fluids helps in the prevention of hypothermia and reduces the incidence of postoperative shivering $[41,42]$. A limitation of our protocol was the absence of data about how often had been used warmed intraoperative fluids and what methods were used to warm them.

We found that general anesthesia added significant intraoperative risks for core hypothermia which is in accordance with previous reports showing a frequent incidence of hypothermia with general anesthesia $[43,44]$. Our results showed a closer relationship concerning the incidence of core hypothermia in the presence of combined epidural anesthesia and general anesthesia and those patients in whom this technique was used were significantly hypothermic at the admission to ICU.

Inadvertent hypothermia during anesthesia is by far the most common perioperative thermal disturbance; this results from a combination of impaired thermoregulation and exposure to the cold environment of the operating 
room [5]. Prevention of hypothermia reduces anesthesiarelated morbidity; so body temperature should be carefully monitored, regardless of anesthetic technique [45] and active warming should be used more frequently because it is a simple and effective technique to avoid hypothermia. In our hospital, and as we could demonstrate with this study, warming rates were very low and the rate of temperature monitoring was even lower, predisposing patients to hypothermia. Like Sessler stated "the minor and major complications of hypothermia are thus well documented. In some patients mild hypothermia is likely to be dangerous. In others it will be uncomfortable and slow recovery". Like him we propose that intraoperative core hypothermia should be avoided and we think the proposed management guidelines should always be observed [46].

Unlike found in an older study [29], we could not show any relationship between hypothermia on arrival at ICU and longer staying in ICU.

We could confirm the results of others about severity of illness of patients as measured by ASA physical status and SAPS II as predictors of prolonged stays in ICU $[47,48]$ and the same happens with the greater amount of intraoperative intravenous fluid administration [16].

Overall mortality in our study was $7,6 \%$ in ICU and $15,7 \%$ in hospital, values that are within the range expected from the corresponding standard mortality ratios of SAPS II $[38,49]$. Hypothermia on admission to ICU was not an independent factor for mortality.

Body mass index, ASA physical status, type of surgery, major surgery, SAPS II score and ICU and hospital LOS were found as statistically significant clinical predictors of death, according to the univariate analysis; whereas according to multiple logistic regression analysis, only the severity of illness of patients as measured by SAPS II and longer ICU stay were confirmed as significantly predictors of death.

A limitation of our protocol is that core temperatures were estimated from the aural canal using an infrared thermometer. Infrared measurements may introduce a degree of variability that could be avoided with carefully positioned thermocouples [37]. However, previous observations state that infrared thermometers are very accurate for determining a patient's temperature when used by those who routinely perform thermometry in hospitalized patients and they can provide accurate estimative of core body temperature [50,51].

A controversial point of our study is the considered definition of hypothermia as $\mathrm{Tc}<35^{\circ} \mathrm{C}$. Others have chosen the same value of core temperature or even a lower one as definition of hypothermia $[3,6,9]$. Meanwhile many approaches have used $36^{\circ} \mathrm{C}$ as the cut off point between hypothermia and normothermia in ICU [52] and studies have considered it in their methodology $[16,53]$.

Improved awareness about perioperative hypothermia and its complications with a strictly adherence to the recommendations about temperature monitoring and thermal management guidelines [46] should play a role in decreasing adverse outcome. It may be advantageous to take steps in the way to decrease prevalence of hypothermia and conduct a study to validate this hypothesis.

\section{Conclusion}

The prevalence of patient hypothermia on arrival at intensive care is very high but, in our results, is not an independent factor for mortality or for staying longer in ICU. The magnitude of surgery, the severity of disease, longer anesthesia periods, the technique of combined epidural and general anesthesia, large amounts of fluids in the operative setting, not using temperature monitoring and a technique to warm patients tend to be risk factors for hypothermia.

All effort to prevent hypothermia should be done, including the more frequently use of body temperature monitoring and methods to warm patients.

\section{Competing interests}

None of the authors have any financial or other relationship that might influence the objectivity when performing the study or preparing the manuscript.

\section{Authors' contributions}

FA participated in conception, design, acquisition of the data, analysis of the data, statistical analysis, critical revision of the manuscript and supervision.

MC participated in conception, design, acquisition of the data, analysis of the data and critical revision of the manuscript.

CS participated in analysis of the data, statistical analyses and drafting of the manuscript.

AN and NL participated in acquisition of the data, analysis of the data and revision of the manuscript.

\section{References}

I. Danzl DF, Pozos RS: Accidental Hypothermia. N Engl J Med 1994, 331:1756-1760.

2. Paton BC: Accidental hypothermia. Pharmacol Ther 1983, 22:33I-377.

3. Vassal T, Benoit-Gonin B, Carrat F, Guidet B, Maury E, Offenstadt G: Severe Accidental Hypothermia Treated in an ICU - prognosis and outcome. Chest 200I, I 20:1998-2003. 
4. Kempainen RR, Brunette DD: The evaluation and management of accidental hypothermia. Respir Care 2004, 49: 192-205.

5. Sessler DI: Mild Perioperative Hypothermia. N Engl J Med 1997, 336: 1730-1737.

6. Frank SM, Beattie C, Christopherson R, Norris EJ, Perler BA, Williams GM, Gottlieb SO: Unintentional hypothermia is associated with postoperative myocardial ischemia. Anesthesiology 1993, 78:468-476.

7. Frank SM, Higgins MS, Breslow MJ, Fleisher LA, Gorman RB, Sitzmann JV, Raff H, Beattie C: The catecholamine, cortisol, and hemodynamic responses to mild perioperative hypothermia. Anesthesiology 1995, 82:83-93.

8. Ream AK, Reitz BA, Silverberg GS: Temperature correction of PCO2 and $\mathbf{p H}$ in estimating acid-base status. Anesthesiology 1982, 56:4I-44.

9. Bush HL, Hydo LJ, Fischer E, Fantini GA, Silane MF, Barie PS: Hypothermia during elective abdominal aortic aneurysm repair: the high price of avoidable morbidity. J Vasc Surg 1995 21:392-400.

10. Ferrel JE Jr, Martin GS: Platelet tyrosine-specific protein phosphorylation is regulated by trombin. Mol Cell Biol 1988, 8:3603-3610.

1I. Valeri CR, Feingold H, Cassidy G, Ragno G, Khuri S, Altschule MD: Hypothermia-induced reversible platelet dysfunction. Ann Surg 1987, 205: 175-181.

12. Michelson AD, MacGregor H, Barnard MR, Kestin AS, Roher MJ, Valeri CR: Irreversible inhibition of human platelet activation by hypothermia in vivo and in vitro. Thromb Haemost 1994, 71:633-640.

13. Roher MJ, Natale AM: Effect of hypothermia on the coagulation cascade. Crit Care Med 1992, 20:1042-1405.

14. Winkler M, Akca O, Birkenberg B, Hetz H, Scheck T, Arkilic CF, Kabon B, Marker E, Grubl A, Czepan R, Greher M, Goll V, Gottsauner-Wolf F, Kurz A, Sessler DI: Aggressive warming reduces blood loss during hip arthroplasty. Anesth Analg 2000, 91:978-984.

I5. Schmied H, Kurz A, Sessler DI, Kozek S, Reiter A: Mild hypothermia increases blood loss and transfusion requirements during total hip arthroplasty. Lancet 1996, 47:289-292.

16. Kongsayreepong S, Chainbundit C, Chadpaibool J, Komoltri C, Suraseranivongse S: Predictor of Core Hypothermia and Surgical Intensive Care Unit. Anesth Analg 2003, 96:826-833.

17. Annadata RS, Sessler DI, Tayefeh F, Kurz A, Dechert M: Desflurane slightly increases the sweating threshold, but produces marked, nonlinear decreases in the vasoconstrition and shivering thresholds. Anesthesiology 1995, 83: | 205-121।

18. Sessler DI: Perioperative heat balance. Anesthesiology 2000 , 92:578-596.

19. Frank SM, Higgins MS, Breslow MJ, Fleisher LA, Gorman RB, Sitzmann JV, Raff H, Beattie C: The catecholamine, cortisol, and hemodynamic responses to mild perioperative hypothermia: a randomized clinical trial. Anesthesiology 1995, 82:83-93.

20. Bilotta F, Pietropaoli P, La Rosa I, Spinelli F, Rosa G: Effects of shivering prevention on haemodynamic and metabolic demands in hypothermic postoperative neurosurgical patients. Anaesthesia 200I, 56:5I4-5I9.

21. Kurz A, Sessler DI, Lenhardt R: Perioperative normothermia to reduce the incidence of surgical-wound infection and shorten hospitalization: Study of Wound Infection and Temperature Infection and Temperature Group. N Engl J Med 1996, 334:1209-1215

22. Frank SM, Fleisher LA, Breslow MJ, Higgins MS, Olson KF, Kelly S, Beattie C: Perioperative maintenance of normothermia reduces the incidence of morbid cardiac events: a randomized trial. JAMA 1997, 277: I I27-I I 34.

23. Wenisch C, Narzt E, Sesseler DI: Mild intraoperative hypothermia reduces production of reactive oxygen intermediates by polymorphonuclear leukocytes. Anesth Analg 1996, 82:810-816.

24. Leslie K, Sessler DI, Bjorksten AR, Moayeri A: Mild hypothermia alters propofol pharmacokinetics and increases the duration of action of atracurium. Anesth Analg 1995, 80:1007-14.

25. Heier T, Caldwell JE, Sessler DI, Miller RD: Mild intraoperative hypothermia increases duration of action and spontaneous recovery of vecuronium blockade during nitrous oxide-isoflurane anesthesia in humans. Anesthesiology 1991, 74:815-819.
26. Macário A, Weinger $M$, Truong $P$, Lee $M$ : Which clinical anaesthesia outcomes are both common and important to avoid? The perspective of a panel of expert anesthesiologists. Anest Analg 1999, 88: |085-109|.

27. Lenhardt R, Marker E, Goll V, Tschernich H, Kurz A, Sessler DI, Narzt $\mathrm{E}$, Lackner F: Mild intraoperative hypothermia prolongs postanesthetic recovery. Anesthesiology 1997, 87:|3|8-|323.

28. Frank SM, Beattie C, Christopherson R, Norris EJ, Rock P, Parker S, Kimball AW Jr: Epidural versus general anesthesia, ambient operating room temperature, and patient age as predictors of inadvertent hypothermia. Anesthesiology 1992, 77:252-257.

29. Berry JM, Garrett K, Clifton GL: Postoperative hypothermia in a tertiary care hospital. Anesthesiology 1999, 91 (Suppl):AII77.

30. Slotman GJ, Jed EH, Burchard KW: Adverse effect of hypothermia in postoperative patients. Am / Surg 1985, I49:495-50 I.

31. Roberts S, Bolton DM, Stoller ML: Hypothermia associated with percutaneous nephrolithotomy. Urology 1994, 44:832-835.

32. Kurz A, Sessler DI, Narzt E, Lenhardt R, Lackner F: Morphometric influences on intraoperative core temperature changes. Anesth Analg 1995, 80:562-567.

33. Just B, Trevien V, Delva E, Leinhardt A: Prevention of intraoperative hypothermia by preoperative skin-surface warming. Anesthesiology 1993, 79:214-218.

34. Kitamura A, Hoshino T, Kon T, Ogawa R: Patient with diabetic neuropathy are at risk of a greater intraoperative reduction in core temperature. Anesthesiology 2000, 92:131|-1318.

35. Hynson JM, Sessler DI: Intraoperative warming therapies: a comparison of three devices. I Clin Anesth 1992, 4:194-199.

36. Amoateng-Adjepong Y, Del Mundo J, Manthous CA: Accuracy of an infrared tympanic thermometer. Chest 1999, I I5(4): 1002-1005.

37. Panzer O, Ghazanfari N, Sessler DI, Yucel Y, Greher M, Akca O, Donner A, Germann P, Kurz A: Shivering and shivering-like tremor during labor with and without epidural analgesia. Anesthesiology 1999, 90:1609-1616.

38. Le Gall JR, Lemeshow S, Saulnier F: A new simplified acute physiology score (SAPSII) based on a European/North American multicenter study. JAMA 1993, 270:2957-2963.

39. El-Gamal N, El-Kassabany N, Frank SM, Amar R, Khabar HA, El-Rahmany HK, Okasha AS: Age-related thermoregulatory differences in a warm operating room environment (approximately $26^{\circ} \mathrm{C}$ ). Anest Analg 2000, 90:694-698.

40. Mills SJC, Holland DJ, Hardy AE: Operative field contamination by the sweating surgeon. Aust N Z J Surg 1999, 70:837-839.

4I. Camus $Y$, Delva $E$, Cohen S, Lienhart A: The effects of warming intravenous fluids on intraoperative hypothermia and postoperative shivering during prolonged abdominal surgery. Acta Anaesthesiol Scand 1996, 40(7):779-82.

42. Smith CE, Desai R, Glorioso V, Cooper A, Pinchak AC, Hagen KF: Preventing hypothermia: convective and intravenous fluid warming versus convective warming alone. J Clin Anesth 1998, I0(5):380-5.

43. Matsukawa T, Kurz A, Sessler DI, Bjorksten AR, Merrifield B, Cheng $C$ : Propofol linearly reduces the vasoconstriction and shivering thresholds. Anesthesiology 1995, 82: I I69-1 I80.

44. Hynson JM, Sessler DI, Moayeri A, McGuire J: Absence of nonshivering thermogenesis in anesthetized adult humans. Anesthesiology 1993, 79:695-703.

45. Cattaneo CG, Frank SM, Hesel TW, El-Rahmany HK, Kim LJ, Tran $\mathrm{KM}$ : The accuracy and precision of body temperature monitoring methods during regional and general anesthesia. Anesthesiology 1996, 84: |327-|33|.

46. Sessler DI: A Proposal for New Temperature Monitoring and Thermal Management Guidelines. Anesthesiology 1998, 89(5): $1298-1300$

47. Wolters $U$, Wolf $T$, Stutzer H, Schroder T: ASA classification and perioperative variables as predictors of postoperative oucome. Br J Anaesth 1996, 77:2 17-222.

48. Stricker K, Rothen HU, Takala J: Resource use in ICU: short-vs. long-term patients. Acta Anaesthesiol Scand 2003, 47:508-5I5.

49. Moreno $R$, Morais $P$ : Outcome prediction in intensive care: results of a prospective, multicentre Portuguese study. Intensive Care Med 1997, 23:177-186.

50. Imamura M, Matsukawa T, Ozaki M, Sessler DI, Nishiyama T, Kumazawa $T$ : The accuracy and precision of four infrared aural 
canal thermometers during cardiac surgery. Acta Anaesthesiol Scand 1998, 42:1222-1226.

5I. Rotello LC, Crawford L, Terndrup TE: Comparison of infrared ear thermometer derived and equilibrated rectal temperatures in estimating pulmonary artery temperatures. Crit Care Med 1996, 24:150I-1516.

52. Sessler DI, Robinstein EH, Moaeyri BA: Physiologic responses to mild perianesthetic hypothermia. Anesthesiology 1991, 75:594-6I0.

53. Insler SR, O'Connor MS, Leventhal MJ, Nelson DR, Starr NJ: Association between postoperative hypothermia and adverse outcome after coronary artery bypass surgery. Ann Thorac Surg 2000, 70:175-|8I.

\section{Pre-publication history}

The pre-publication history for this paper can be accessed here:

http://www.biomedcentral.com/1471-2253/5/7/prepub

Publish with Bio Med Central and every scientist can read your work free of charge

"BioMed Central will be the most significant development for disseminating the results of biomedical research in our lifetime. "

Sir Paul Nurse, Cancer Research UK

Your research papers will be:

- available free of charge to the entire biomedical community

- peer reviewed and published immediately upon acceptance

- cited in PubMed and archived on PubMed Central

- yours - you keep the copyright 